\title{
Detection of canine allograft lung rejection by pulmonary lymphoscintigraphy
}

We previously demonstrated that lymphoscintigraphy could be used to study pulmonary lymphatic flow. Radiocolloids, high-molecular-weight proteins tagged with radioactive markers, are injected percutaneously in the periphery of the lung. These molecules enter the lymph, are transported via lymphatic channels, and concentrate in the tributary hilar and mediastinal lymph nodes, where they can be visualized by nuclear scan. The goal of this study was to determine whether pulmonary lymphoscintigraphy could be used to detect allograft rejection after lung transplantation. Thirteen mongrel dogs underwent left lung allotransplantation. Cyclosporine $15 \mathrm{mg} / \mathrm{kg}$ per day and azathioprine $1 \mathrm{mg} / \mathrm{kg}$ per day were given orally for postoperative immunosuppression. Lymphoscintigraphic studies were obtained 1 week after the operation and then at weekly intervals. In five dogs (group A), immunosuppression was continued until the animal died or was put to death 6 weeks later. Lymphoscintigraphy demonstrated reestablishment of lymphatic drainage between the lung graft and the mediastinum in all the animals 2 to 4 weeks after transplantation. In eight dogs (group B), immunosuppression was discontinued after reestablishment of graft lymphatic drainage was documented by two consecutive lymphoscintigraphic studies. The dogs continued to be studied with weekly scans. In group B, lymphatic drainage from the lung graft to the mediastinum disappeared 1 to 4 weeks after immunosuppression was stopped. Rejection was diagnosed clinically and confirmed histologically with open lung biopsies and/or autopsies in all animals. This study shows that canine allograft lung rejection is associated with disappearance of lymphatic drainage from lung graft to mediastinum, which can be documented by pulmonary lymphoscintigraphy, a minimally invasive technique that can be easily repeated. Pulmonary lymphoscintigraphy may be useful for early detection of lung allograft rejection. (J Thorac CardiovasC Surg 1994;108:253-8)

Renato Ruggiero, $\mathrm{MD}^{\mathrm{a}}$ (by invitation), Robert Fietsam, Jr., $\mathrm{MD}^{\mathrm{a}}$ (by invitation), Gregory A. Thomas, $\mathrm{MD}^{\mathrm{a}}$ (by invitation), Jaroslaw $\mathrm{Muz}, \mathrm{MD}^{\mathrm{b}}$ (by invitation), Ronnie H. Farris, CNMT ${ }^{b}$ (by invitation), Thomas A. Kowal, $\mathrm{PA}^{\mathrm{a}}$ (by invitation), Jonathan L. Myles, $\mathrm{MD}^{\mathrm{c}}$ (by invitation), Larry W. Stephenson, MD, ${ }^{\mathrm{a}}$ and

Frank A. Baciewicz, Jr., MD (by invitation), Detroit, Mich., and Cleveland, Ohio

$\mathrm{P}$ capable of detecting pulmony is a nuclear technique phoscintigraphy used in a canine model of allograft lung transplantation has demonstrated that lymphatic drain-

From the Divisions of Cardiothoracic Surgery ${ }^{a}$ and Nuclear Medicine, ${ }^{b}$ Wayne State University, School of Medicine, Detroit, Mich., and the Department of Pathology, ${ }^{\mathrm{C}}$ Cleveland Clinic Foundation, Cleveland, Ohio.

Read at the Seventy-third Annual Meeting of The American Association for Thoracic Surgery, Chicago, Ill., April 25-28, 1993.

Address for reprints: Frank A. Baciewicz, Jr, MD, Harper Hospital, Suite 228, 3990 John R, Detroit, MI 48201.

Copyright ${ }^{\circledR} 1994$ by Mosby-Year Book, Inc.

$0022-5223 / 94 \$ 3.00+0 \quad \mathbf{1 2} / \mathbf{6} / \mathbf{5 3 2 1 2}$ age from the allograft to the mediastinum is reestablished 2 to 4 weeks after lung transplantation. ${ }^{.}$

The goal of this study was to evaluate whether lung lymphoscintigraphy could be used after lung transplantation to detect acute lung allograft rejection.

\section{Materials and methods.}

Thirteen mongrel dogs, 20 to $30 \mathrm{~kg}$ in weight, underwent left lung allotransplantation. The animals were treated and operated on in accordance with the "Guide for the Care and Use of Laboratory Animals" published by the National Institutes of Health (NIH Publication No. 86-23, revised 1985). The lung grafts were harvested from donor mongrel dogs matched in size and were implanted according to standard surgical technique. ${ }^{2,3}$ The bronchial anastomosis was telescoped with no 


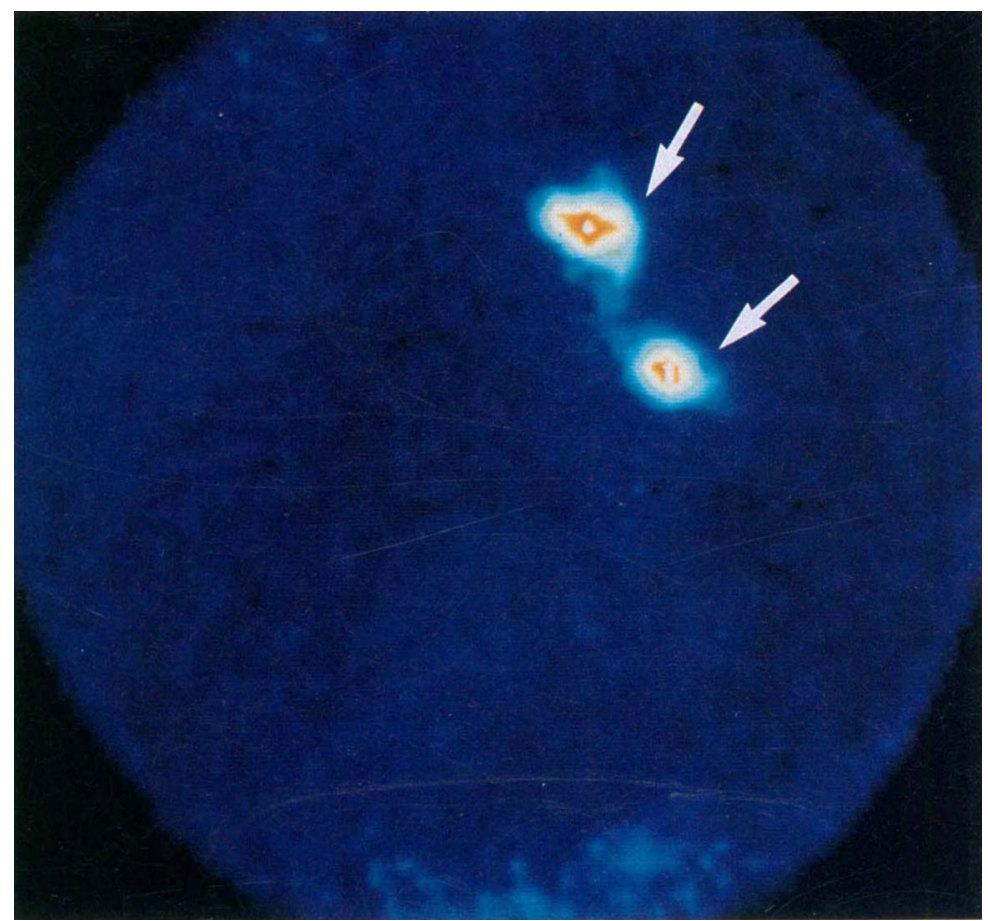

Fig. 1. Left lung lymphoscintigraphic study 1 week after lung transplantation. Anteroposterior view of chest. Left upper and lower lobe injection sites marked with large arrows. No mediastinal nodes are seen. Negative study.

Table I. Results of lymphoscintigraphic scans

\begin{tabular}{|c|c|c|c|c|c|c|c|c|c|c|c|}
\hline \multirow[b]{2}{*}{ Dog No. } & \multicolumn{11}{|c|}{ Postoperative time } \\
\hline & $I w k$ & $2 w k$ & $3 w k$ & $4 w k$ & $5 w k$ & $6 w k$ & $7 w k$ & $8 w k$ & $9 w k$ & $10 w k$ & $11 w k$ \\
\hline \multicolumn{12}{|l|}{ Group $A$} \\
\hline 1 & - & + & + & + & + & + & & & & & \\
\hline 2 & - & + & & & & & & & & & \\
\hline 3 & - & + & + & + & + & + & & & & & \\
\hline 4 & - & - & + & & + & + & & & & & \\
\hline 5 & - & - & - & + & & + & & & & & \\
\hline \multicolumn{12}{|l|}{ Group B } \\
\hline 6 & - & + & +1 & + & + & - & - & & & & \\
\hline 7 & - & + & +1 & + & +1 & + & & - & - & & \\
\hline 8 & - & + & +1 & - & & & & & & & \\
\hline 9 & - & + & +1 & + & - & & + & - & - & & \\
\hline 10 & - & + & +1 & + & - & - & & & & & \\
\hline 11 & - & - & + & +1 & - & - & & & & & \\
\hline 12 & - & - & + & +1 & + & - & - & - & & & \\
\hline 13 & - & - & - & + & $+/$ & + & + & - & - & - & - \\
\hline
\end{tabular}

- , Negative scan, no mediastinal nodes visualized; + , positive scan, mediastinal nodes visualized; /, immunosuppression off.

omentopexy. ${ }^{4}$ Immunosuppression consisted of methylprednisolone $500 \mathrm{mg}$ intravenously immediately after graft reperfusion, cyclosporine $15 \mathrm{mg} / \mathrm{kg}$ per day, and azathioprine $1 \mathrm{mg} / \mathrm{kg}$ per day orally starting on the first postoperative day.

The animals underwent lymphoscintigraphic study of the left lung allograft for the first time 1 week after the operation and then at weekly intervals. The technique of pulmonary lymphoscintigraphy consisted of percutaneous injection of $0.2 \mathrm{mCi}$ of technetium $99 \mathrm{~m}$ antimony sulphide colloid into the periphery of the left upper and lower lobes. The animals were slightly sedated during the injection.

Twenty-four hours after the injection, the dogs underwent 


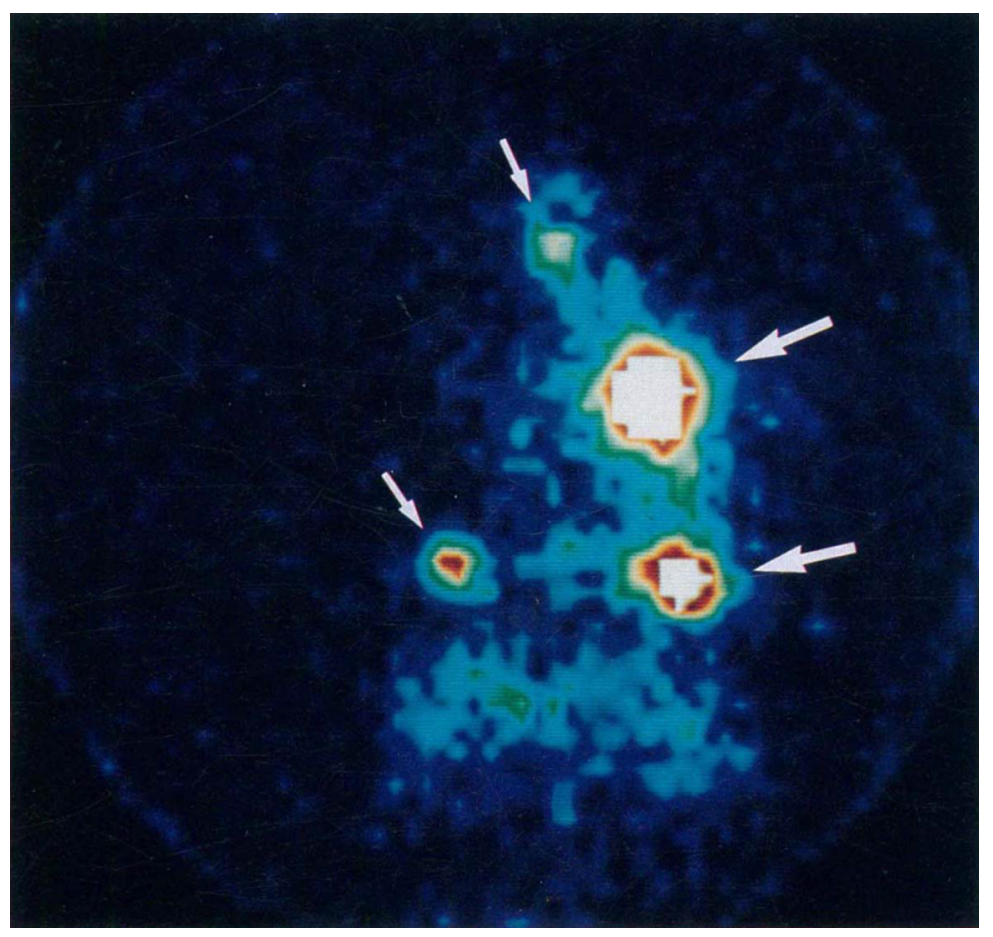

Fig. 2. Left lung lymphoscintigraphic study 3 weeks after lung transplantation, during immunosuppression (same dog as in Fig. 1). Anteroposterior view of chest. Left upper and lower lobe injection sites marked with large arrows. Mediastinal nodes marked with small arrows. Positive study.

scintigraphic studies of the chest and upper part of the abdomen with a Siemens 7500 ZLS gamma camera (Siemens Gamma Sonics, Inc., Des Plaines, Ill.). Images of the lung and the mediastinum were obtained in the anteroposterior and lateral projections. The studies were conducted with the animals anesthetized and endotracheally intubated. Nuclear scans were repeated once a week and read by a nuclear medicine specialist blinded to the study protocol. The scans were considered positive when mediastinal lymph nodes were visualized, indicating reestablished lymphatic drainage from lung to mediastinum. The scans were considered negative when no mediastinal lymph nodes were seen.

Five dogs (group A) received immunosuppression for the 6-week duration of the study. After the lymphoscintigraphic study became positive the animals underwent either open lung biopsies or terminal autopsies. Eight dogs (group B) had immunosuppression discontinued after two consecutive lymphoscintigraphic studies showed reestablished lymphatic drainage from lung allograft to mediastinum. With the animals off the immunosuppressive therapy, open lung biopsy specimens were obtained after lymphoscintigraphic studies became negative. Autopsies were performed after the animals died or were put to death.

\section{Results}

In the five group A dogs, lymphoscintigraphy did not visualize mediastinal nodes 7 days after the operation. In three dogs, mediastinal nodes were first detected 2 weeks after transplantation, in the fourth $\operatorname{dog} 3$ weeks after the operation, and in the fifth $\operatorname{dog}$ at 4 weeks. One animal died of pulmonary infarction a few days after the mediastinal nodes were detected for the first time. The other four dogs in this group were studied with lymphoscintigraphy for 6 consecutive weeks. In all cases subsequent scans confirmed the presence of mediastinal nodes, indicating reestablishment of lymphatic drainage between lung allograft and mediastinum. Open lung biopsy specimens showed no evidence of rejection. At autopsy either mild lung allograft rejection or normal lung was found.

The eight dogs in group B underwent left lung allograft transplantation followed by immunosuppression and weekly lymphoscintigraphic scans. Mediastinal nodes were not detected in any of the animals 1 week after transplantation (Fig. 1). In five dogs mediastinal nodes were visualized for the first time 2 weeks after the operation. Two dogs had mediastinal nodes visualized at 3 weeks and one dog at 4 weeks (Fig. 2). In all cases reestablishment of lymphatic drainage between the lung and the mediastinum was confirmed by a second lymphoscintigraphic scan 1 week later. After the second positive scan, immunosuppression was discontinued in all animals and never restarted. Two dogs showed no sign of mediastinal 


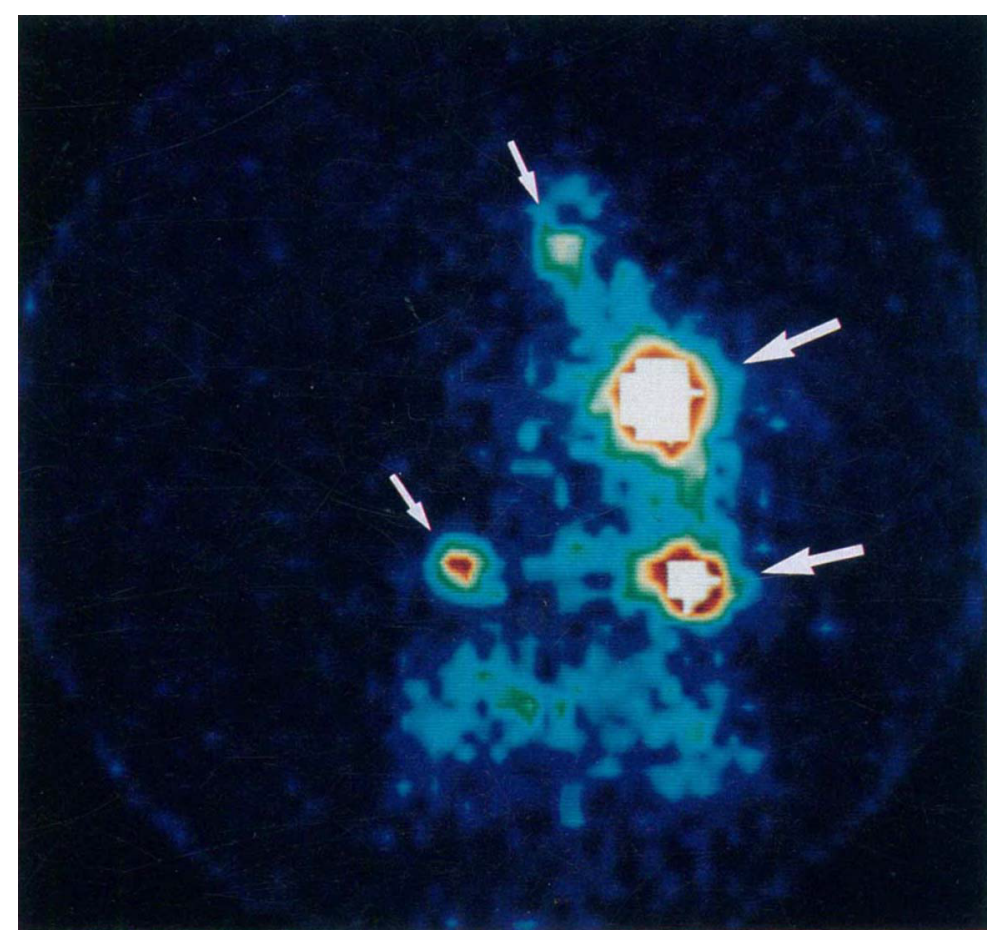

Fig. 3. Left lung lymphoscintigraphic study 2 weeks after immunosuppression was discontinued (same dog as in Figs. 1 and 2). Anteroposterior view of chest. Left upper and lower lobe injection sites marked with large arrows. No mediastinal nodes. Study became negative again, which suggests disappearance of lymphatic drainage between lung and mediastinum.

nodes 1 week after immunosuppression was stopped. In three animals mediastinal nodes disappeared after 2 weeks without immunosuppression, in two dogs after 3 weeks, and in the last dog after 4 weeks (Fig. 3). Once lymphatic drainage from the lung allograft to the mediastinum disappeared, the subsequent lymphoscintigraphic studies remained negative in all animals. After immunosuppression was stopped, rejection was diagnosed clinically in all dogs and confirmed histologically by open lung biopsies that showed perivascular mononuclear infiltrates extending into the alveolar septa. All animals died of complications of lung rejection between 1 and 6 weeks after immunosuppression was stopped. At autopsy the lung showed diffuse mononuclear cell infiltrates with areas of necrosis and vasculitis.

Table I summarizes results of the lymphoscintigraphic scans in groups A and B.

\section{Discussion}

The diagnosis of graft rejection after lung transplantation remains a challenging problem with significant clinical implications. Acute rejection often develops in the first few weeks after lung transplantation. It is suspected from clinical signs, laboratory results, and radiological findings ${ }^{5-8}$ but can be diagnosed with certainty only histologically. Graft tissue can be obtained either by open lung biopsy or by transbronchial biopsy, both invasive procedures that cannot be repeated frequently. ${ }^{9-11}$

Several investigators have attempted to identify early markers of rejection. Celland and associates ${ }^{12}$ have shown differences in lymphocyte cell count in bronchoalveolar lavage samples obtained during rejection from heart-lung transplant recipients. Other researchers have demonstrated an increase in cytotoxic $\mathrm{T}$ cells, macrophages, and polymorphonuclear cells in bronchoalveolar lavage specimens obtained in the setting of acute lung rejection. 13-16

Serum markers of rejection have also been studied, the most promising of which is the level of $\mathrm{T}$ cell interleukin-2 receptors. ${ }^{17,18}$ Deterioration in pulmonary function tests has been associated with chronic rejection, but changes in pulmonary function tests do not accurately predict early rejection. ${ }^{19}$

The importance of lymphatic drainage from lung allograft to mediastinum after lung transplantation is not well understood. Eraslan, Turner, and Hardy ${ }^{20}$ demonstrated in a canine model of lung reimplantation that lymphatic drainage from lung to mediastinum is reestablished around the twelfth postoperative day after inter- 
ruption of hilar lymphatics. Recently Wang and associates $^{21}$ showed that rat antibody response to particulate antigens instilled intrabronchially was severely impaired after interruption of hilar lymphatics with possible increased susceptibility to lung infections. After reestablishment of lymphatic drainage from native lung to mediastinal lymph nodes, the antibody response returned to normal.

In a previous study we used pulmonary lymphoscintigraphy in a canine model of lung transplantation to demonstrate that lymphatic drainage from lung allograft to mediastinum is reestablished as early as the second postoperative week. ${ }^{1}$ The technique consists of percutaneous injection into the lung of radiocolloids, large-sized protein molecules tagged with radioactive isotopes that are absorbed only through the lymph and concentrated in tributary lymph nodes that can then be visualized scintigraphically. $22-25$

In the present study, pulmonary lymphoscintigraphy was used to evaluate the relationship between lung rejection and pulmonary lymphatic drainage after lung transplantation. The control group of five dogs showed that lymphatic drainage from the grafted lung to the mediastinum is reestablished 2 to 4 weeks after transplantation. The lymphatic scans remained positive while these animals were receiving immunosuppression. In a second group of eight dogs, immunosuppression was stopped after reestablishment of lymphatic drainage from the lung graft to the mediastinum was documented for 2 consecutive weeks. Acute lung rejection, which was diagnosed clinically and confirmed by open lung biopsy, developed after immunosuppression was discontinued. Between 1 and 4 weeks after immunosuppression was stopped, lymphoscintigraphic scans became negative in all animals, suggesting disappearance of the previously reestablished lymphatic drainage from lung graft to mediastinum. All subsequent lymphoscintigraphic scans remained negative.

Why lymphatic drainage from lung allograft to mediastinum disappears during rejection is not clear. Possible mechanisms include lymphatic obstruction resulting from perivascular accumulation of immunocompetent cells in the rejected graft or changes in interstitial pressure affecting entrance of fluids and cells into the pulmonary lymphatics.

One limitation of pulmonary lymphoscintigraphy is that it relies on reestablishment of lymphatic drainage, a process that occurs over a 2- to 4-week period after lung transplantation. During this time, episodes of early acute rejection might not be detected. Pulmonary lymphoscintigraphy has several advantages when compared with other techniques used to detect rejection after lung trans- plantation. Lymphoscintigraphy is minimally invasive, requiring only percutaneous injection of the periphery of the lung graft through the chest wall with a fine-gauge needle. In the clinical setting this could be easily performed with local anesthesia as an outpatient procedure and could be repeated as often as needed. The procedure has been well tolerated in dogs with no significant complications observed after more than 100 injections. The dose of radioactive material is small, with no significant hazards to the animals or the personnel involved.

We conclude that with the technique of pulmonary lymphoscintigraphy it is possible to demonstrate a correlation between decreased lymphatic drainage from lung allograft and rejection in an animal model of lung transplantation. This study suggests that pulmonary lymphoscintigraphy may be useful in the diagnosis of acute lung rejection.

\section{REFER EN CES}

1. Ruggiero R, Muz J, Fietsam R Jr, et al. Reestablishment of lymphatic drainage after canine lung transplantation. $J$ ThORAC CARDIOVASC SURG 1993;107:167-71.

2. Veith FJ, Richards K. Improved technique for canine lung transplantation. Ann Surg 1970;171:553-8.

3. Cooper JD, Pearson FG, Patterson GA, et al. Technique of successful lung transplantation in humans. $\mathbf{J}$ THORAC Cardiovasc Surg 1987;93:173-81.

4. Calhoon JH, Grover FL, Gibbons WJ, et al. Single lung transplantation: alternative indications and technique. $\mathbf{J}$ Thorac Cardiovasc Surg 1991;101:816-25.

5. Griffith BP, Durham SJ, Hardesty RL, et al. Acute rejection of the heart-lung allograft and methods of its detection. Transplant Proc 1987;19:1527-30.

6. Lawrence EC. Diagnosis and management of lung allograft rejection. Clin Chest Med 1990;11:269-78.

7. Kirby TJ, Mehta A, Rice TW, et al. Diagnosis and management of acute and chronic lung rejection. Semin Thorac Cardiovasc Surg 1992;4:126-31.

8. Shumway SJ. Rejection and immunosuppression in lung transplantation. Chest Surg Clinic 1993;3:145-55.

9. Higenbottan TW, Stewart S, Wallwork J. Transbronchial lung biopsies to diagnose lung rejection and infection of heart-lung transplants. Transplant Proc 1988(Suppl 1); 20:767-9.

10. Starnes VA, Theodore J, Oyer PE, et al. Pulmonary infiltrates after heart-lung transplantation: evaluation by serial transbronchial biopsies. J THORAC CARDIOvaSC SURG 1989;98:945-50.

11. Scott JP, Smyth RL, Higenbottan TW, et al. Transbronchial biopsies after lung transplantation. J THORAC CARDIOVASC SURG 1991;101:935-47.

12. Celland C, Higenbottan TW, Smyth RL, et al. Lymphocyte count in bronchoalveolar lavage during acute rejection and infection in heart-lung transplantation. Am Rev Respir Dis 1989;139:A242. 
13. Gryzan S, Paradis IL, Hardesty RL, et al. Bronchoalveolar lavage in heart-lung transplantation. J Heart Transplant 1985;4:414-6.

14. Zeevi A, Rabinovitch H, Paradis E, et al. Lymphocyte activation in bronchoalveolar lavages from heart-lung transplant recipients. Transplant Proc 1988;20:189-92.

15. Emeson EE, Norin AJ, Veith FJ. Lectin dependent cell mediated cytotoxicity: a new and simple method to quantitate cytotoxic $\mathrm{T}$ cell activity in dogs. Transplantation 1982;33:365-9.

16. Dal Col RH, Rabinovich H, Herlan RB, et al. Donor specific cytotoxicity testing: an advance in detecting pulmonary allograft rejection. Ann Thorac Surg 1990;49:754-8.

17. Holland VA, Brousseau KP, Berger MB, et al. Soluble interleukin-2 receptors following heart, heart-lung and lung transplantation. Clin Res 1988;36:18A.

18. Lawrence EC, Holland VA, Young JB, et al. Dynamic changes in soluble interleukin-2 receptors levels after lung or heart lung transplantation. Am Rev Respir Dis 1989; 140:789-96.

19. Otulana BA, Higenbottan TW, Scott JP, et al. Pulmonary function monitoring allows diagnosis of rejection in heartlung transplant recipients. Transplant Proc 1989;21: 2583-4.

20. Eraslan S, Turner MD, Hardy JD. Lymphatic regeneration following lung reimplantation in dogs. Surgery 1964; 56:970-3

21. Wang F, Winter JB, Dam M, et al. Influence of interrupted pulmonary lymph drainage on antibody responses in hilar-stripped lungs. J Heart Lung Transplant 1992; 11 : S21 5-20.

22. Garzon OL, Palcos MC, Radicella R. A technetium- $99 \mathrm{~m}$ labeled colloid. Int J Appl Radiat Isot 1965;16:613.

23. Langhammer $\mathrm{H}$, Hor $\mathrm{G}$, Pabst $\mathrm{HW}$, et al. Scanning mediastinal lymph nodes. J Nucl Med 1969;10:749-51.

24. Warbick A, Ege GN, Henkelman RM, et al. An evaluation of radiocolloid particle sizing techniques. J Nucl Med 1977;18:827-34.

25. Ege GN, Warbick A. Lymphoscintigraphy: a comparison of ${ }^{99} \mathrm{Tc}^{\mathrm{m}}$ antimony sulphide colloid and ${ }^{99} \mathrm{Tc}^{\mathrm{m}}$ stannous phytate. Br J Radiol 1979;52:124-9.

\section{Discussion}

Dr. John H. Kennedy (Cambridge, England). When you use the term pulmonary lymph drainage, I assumed you must have had a cannula in the lymphatic system. Then you had the chest open and could do pulmonary biopsies. I would suggest that the lesion you are studying must be at the molecular level, and what you need to have is a study of the distribution volume for your macromolecule, that is, counts in tissue versus counts in fluid, in this case, lymph.

Dr. Robert J. Keenan (Pittsburgh, Pa.). I have two questions. First, can you differentiate acute rejection from infection? This is clearly a circumstance where certain viral infections, even bacterial infections, can give a histologic and clinical picture vèry similar to pulmonary rejection. The second question relates to the timing of the disappearance of lymphatic drainage during rejection: Have you looked at the progression of histology off immunosuppression and does the disappearance in the lymphatic drainage precede, coincide with, or follow the histologic progression of rejection?

Dr. Thomas M. Egan (Chapel Hill, N.C.). This corroborates our clinical observation that we often see increased pleural drainage in the first week to 10 days after transplantation when we see an episode of acute rejection. Occasionally, several weeks after transplantation a pleural effusion will develop around the lung that we believe is being rejected. I think that may relate to obstruction to lymphatic drainage.

We also see a change in compliance of the lung, presumably because of increased interstitial fluid in the lung. Could your results simply represent a pressure phenomenon that is occurring outside the new lymphatic channels that are trying to reestablish at the hilum? What I am getting at is that this may not be a cause of rejection but may be simply a consequence of some of the changes that are occurring in the interstitium of the lung.

Dr. Ruggiero. I would like to thank all the discussants for their comments. In answer to Dr. Kennedy, the technique that we developed is minimally invasive. A 2 -inch long, 27-gauge needle was used to inject the contrast material percutaneously in the periphery of the lung. Our animals required intravenous sedation, but in a clinical setting the procedure could be easily performed under local anesthesia. Regarding your suggestion of assessing the technique at the molecular level, we agree that this could provide interesting information but we did not have the opportunity to address this particular issue.

Dr. Keenan, your first question was whether it was possible to differentiate between injection and infection using the technique of pulmonary lymphoscintigraphy. After the animals were taken off immunosuppression they all had clinical and radiographic evidence of respiratory failure consistent with diagnosis of graft rejection. This was confirmed histologically with open lung biopsy and autopsy. In an effort to identify the presence of pulmonary sepsis, two animals were examined with a flexible bronchoscope with bronchoalveolar lavage, but the results were not conclusive, so that a clear correlation could not be made with lymphoscintigraphic scans obtained around the same time. For this question to be answered conclusively, pulmonary lymphoscintigraphy needs to be used in an animal model of lung infection.

Dr. Keenan then asked about the timing of open lung biopsy. Every dog underwent open lung biopsy as soon as the lymphoscintigraphic study became negative. Autopsies were also performed in all animals when they died.

Finally, we agree with Dr. Egan's comment that interstitial pulmonary pressure could influence lymphatic drainage from lung allograft to mediastinum. I would like to add that we have two additional animals that we did not include in this report. These two dogs initially underwent the same protocol that was just described. After immunosuppression was discontinued lung rejection developed with conversion of lymphoscintigraphic scans from positive to negative. In these two dogs, though, immunosuppression was restarted and pulsed steroids were also given. Both animals improved clinically and in both subsequent pulmonary lymphoscintigraphic scans became again positive, suggesting that successful treatment of episodes of rejection is associated with improvement in lymphatic drainage from lung graft to mediastinum. 